\title{
Designing for Spectators and Coaches: Social Support in Pervasive Health Games for Youth
}

\author{
Erika Shehan Poole ${ }^{1}$, Elsa Eiríksdóttir ${ }^{2}$, Andrew D. Miller ${ }^{3}$, Yan $\mathrm{Xu}^{3}$, Richard Catrambone ${ }^{4}$, Elizabeth D. Mynatt ${ }^{3}$ \\ Information Sci. \& Technology ${ }^{1}$ \\ The Pennsylvania State University \\ University Park, PA USA \\ epoole@ist.psu.edu \\ Reykjavik Academy ${ }^{2}$ \\ Reykjavik, Iceland \\ elsa@timbur.is \\ College of Computing ${ }^{3} \&$ School of Psychology $^{4}$ \\ Georgia Institute of Technology \\ Atlanta, GA USA \\ \{andrew.miller, yxu7, rc7, mynatt\}@gatech.edu
}

\begin{abstract}
Active video games and other technology-based interventions can promote physical activity participation in children and adolescents, particularly those who are uninterested in traditional sports or lack access to gyms, sports clubs, or safe neighborhood recreational environments. Yet simply placing a game console in a home or school might not be sufficient for changing physical activity behaviors. Rather, social support and opportunities for structured group activity may be important aspects of pervasive health games. We know little, however, about how to design active video games and other technologybased interventions in ways that explicitly allow for the provision of social support by other players as well as "spectators" of the game. Based on the results of a longitudinal study of an active video game used in American schools, this paper contributes design recommendations for features in pervasive health games that explicitly encourage social support.
\end{abstract}

Keywords-active video games; human-computer interaction; social support; youth

\section{INTRODUCTION}

Active video games and other technology-based interventions might provide a way to increase physical activity in children and adolescents, particularly those who are uninterested in traditional sports or lack access to gyms, sports clubs, or safe neighborhood recreational environments. Yet simply placing a game console in a home or school might not be sufficient for changing physical activity behaviors $[1,2]$. The support of other is an important factor in increasing youth physical activity participation [1]. We know little, however, about how to design active video games and other technologybased interventions for youth in ways that explicitly allow for the provision of social support by other players as well as "spectators" who observe gameplay.

In this paper, we provide guidelines that can assist intervention and technology developers in creating compelling pervasive health game user experiences, by explicitly considering social support in the design process. We base our guidelines in the results of a longitudinal study of a pervasive health intervention for children and young adolescents. This intervention, called the American Horsepower Challenge (AHPC), aimed to increase physical activity in the context of a school setting. In this paper, we address the following questions:
1. What sorts of support did the players of the AHPC receive from friends, parents, and teachers?

2. How - if at all-did the user interface of the game facilitate social support?

3. What unmet opportunities for provision of social support in pervasive health games did this intervention reveal?

The contribution of this paper is a set of design recommendations that can be applied to future pervasive health interventions for youth.

\section{RELATED WORK}

A long-standing body of literature in the behavioral sciences has examined correlates of physical activity in children and adolescents. These factors range from the individual level (gender, individual preferences, intention to be active, previous physical activity participation), to family (parent obesity, willingness to pay fees for participation in lessons), to environmental (having access to programs and locations for being active) [3-5]. In a number of studies, social support from other people has been identified as having a positive impact on physical activity and other health outcomes. [6]. Social support is a broad term; it can mean a number of things including emotional support (e.g. empathetic listening), instrumental support (e.g. providing money), informational support (e.g. educating or discussing), companionate support (e.g. sharing experiences), or esteem support (e.g. encouraging a person). [7, 8]. For the purposes of this paper, we focus particularly on informational support, companionate support, and esteem support. We also examine perceptions of support; research indicates that an individual's belief in being supported - whether or not he or she is actually supported - can positively impact health outcomes [8].

Social support from parents is especially important for school-age children. During this period of childhood, parents serve not only as role models and sources of information, but they also advocate, reinforce, and meter access to environments and programs for being physically active [9]. Adolescents, in contrast, may be more influenced by the activity levels of their peers than their parents [10]. Since the target audience of the AHPC included both school-age 
Players view individual and team standings via online AHPC game
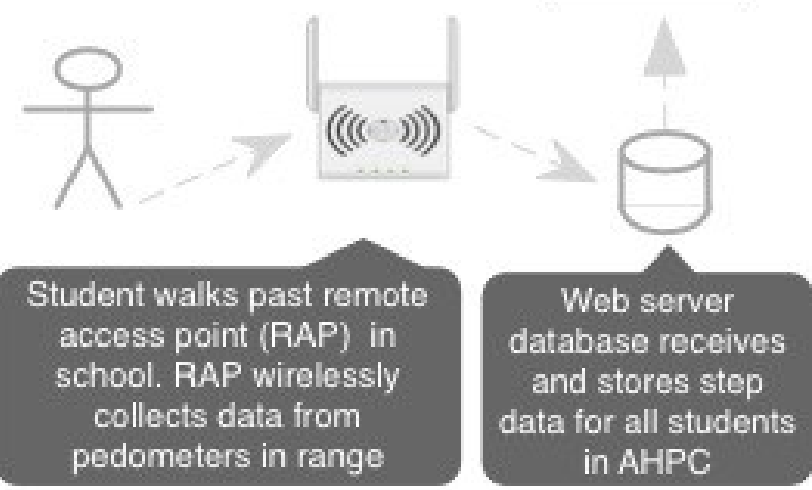

Figure 1.

Illustration of step data collection mechanisms

children and early adolescents, we examined support from family as well as peers.

\section{METHODS}

The research presented in this paper was conducted in compliance with the Helsinki Declaration. The Georgia Tech Institutional Review Board reviewed and approved the research protocol. All participants signed consent/assent forms prior to participating in the deployment.

\section{A. Overview}

Developed by Humana Games For Health and sponsored by the Humana Foundation ${ }^{1}$, the AHPC used real-world fitness data collected by wireless sensors as input to a multiplayer online game. This game aimed to increase daily physical activity of school-age children and early adolescents, and broadened opportunities for children to be more active; even those with little skill in traditional sports could compete in an athletic competition for their school.

The primary activity of the AHPC was a virtual "race" in which schools competed against other schools participating in the program. Students in the competition wore pedometers measuring physical activity; each bout of walking or running - no matter the duration - earned points for the school. Students and teachers interacted with the AHPC via a password-protected game website accessible from school and home. It is important to note that this intervention did not experimentally manipulate social support; instead, we

1 The Humana Foundation is the philanthropic arm of Humana, Inc., a health benefits company. The authors of this paper did not participate in the design or the deployment of the system, but instead served as independent evaluators. observed social support practices as they emerged naturally during the course of the program.

\section{B. Participants}

Before our research group's involvement with the project, the Humana Foundation recruited schools based on having high participation in the National School Lunch Program, a federally assisted meal program in the US for low-income students; on average, $73.5 \%$ of students at AHPC schools received free or reduced lunch. The schools were situated in a range of environments, from large cities to rural areas. Thirtyseven schools continued in the AHPC across all three rounds of the challenge; 1,377 students started in the first round (Spring 2009) and 1,743 students participated in at least one of the three rounds. Most students were in $6^{\text {th }}$ grade (age 10-11) when they began the Challenge and in $7^{\text {th }}$ grade (age 12-13) when the Challenge ended. Each school handled participant recruitment differently. Some schools held random lotteries, while at others teachers selected students based on characteristics such as "responsibility." At the majority of schools, 20 students participated in the program at a given time. Over the course of the deployment, students joined or left the program for various reasons, such as lack of interest or moving away from the school district. Some teachers who taught only $6^{\text {th }}$ grade proactively chose to recruit different students in the second year of the program, due to losing daily access to students when they started the $7^{\text {th }}$ grade.

\section{Procedure}

During the competition, each child wore a small, unobtrusive shoe-mounted pedometer with a wireless transmitter during the competition (Actiped, manufacturer: Fitlinxx). As illustrated in Fig. 1, steps from the pedometers were wirelessly uploaded to a base station when a student walked within range of it (typically this base station was placed in a high-traffic area of the school). Step data were available on the game website within eight hours. Students could use the web game interface to check their steps, see their classmates' characters and status, purchase items for their avatars, and see their school's total compared to other schools. The website featured a "horserace" metaphor; a customizable cartoon horse character represented each student, and the horses from each school sat in a customizable school bus that traveled around a racetrack with other schools in the competition. Teachers had their own version of the website that allowed them to customize the school's bus, keep track of students' step counts, and perform basic administrative tasks.

\section{Data Collection}

Pedometer and Web Usage Data. We collected website usage and pedometer log data from each child to supplement self-reports. In total, we examined 14 weeks of individual and aggregate data (including the two 4-week rounds and one 5week round and a preliminary baseline week before the challenge began). We analyzed step patterns across rounds, within rounds, and within each week, which are outlined more fully in [11]. In the step log data, a few entries had empty values for the step count due to technical problems such as 
low battery of the pedometer and network problems. We discarded those entries for purposes of data analysis.

Site Visits. We conducted interviews with students, teachers, and administrators as well as and focus groups with students at 15 schools enrolled in the program.

Surveys. We distributed surveys to each participating school's students, parents, and the teachers involved in the challenge. Teacher surveys asked about the availability of facilities, curriculum, and extra-curricular activities for student physical activity. The parent survey included questions about neighborhood characteristics, the family's physical activity participation, the child's leisure time activities, and support provided by the parents that may enable physical activity participation (e.g. paying for lessons, providing transportation). Student surveys addressed attitudes toward and participation in physical activity, experiences with the intervention, and social support for physical activity. In surveys distributed during game rounds 2-3, social support was measured using the Social Support for Exercise Survey [12], a scale in which respondents rate how frequently during the past month people in their lives have showed social support for physical activities, as represented by 13 statements such as "exercised with me", "gave me encouragement to stick with my exercise program", and "helped plan activities around my exercise". Frequency was coded on a scale from 1 to 5 , where a higher number represents higher frequency (e.g., 1 equals never and 5 equals very often). On each survey, the student answered the scale three times: the first asking about family support, the second asking about peer support, and the third asking about teacher support. In fall 2009, 202 parent surveys were returned. In fall 2009, 210 student surveys were returned and in spring 2010, 130 student surveys were returned. In spring 2010, 19 teachers representing 19 schools returned surveys. For purposes of this paper, we restrict our data analysis to the second year of the program, as the game interface changed between the first and second round; additionally, roughly one-third of the participating schools recruited new players during the second and third rounds (typically because the facilitating teacher only taught one grade level, and did not have classes with the students from round 1).

\section{RESULTS}

Overall, students were positive about their participation in the program, with $51 \%$ rating the program at its conclusion as "awesome" (5/5 on a Likert scale; mean response was 4.17). The program also led to moderate increases in daily physical activity as compared to a baseline data collection period; those findings are discussed more thoroughly in [11]. In the remainder of this paper, we turn our focus to social support and how it was enacted within the program. Specifically, we examine whether and how various groups in the players lives provided social support throughout the competition through having conversations about physical activity, encouraging physical activity, providing reminders, and joining students in accruing physical activity. We also discuss social comparison
TABLE 1: SURVEY DISTRIBUTION

\begin{tabular}{clc}
\hline SURVEY TYPE & DATE & GAME Round \\
\hline Student & & \\
Survey 1 & April 2009 & 1 \\
Survey 2 & November 2009 & 2 \\
Survey 3 & January 2010 & 3 \\
Survey 4 & February 2010 & 3 \\
Parent & & \\
Survey 1 & April 2009 & 1 \\
Survey 2 & November 2009 & 2 \\
Teacher & & \\
Survey 1 & April 2009 & 1 \\
Survey 2 & February 2010 & 3 \\
\hline
\end{tabular}

that occurred during game play, as well as temporal characteristics of step data that may shed light on opportunities to explicitly design for social support in pervasive health games.

\section{A. Conversations}

Conversations about physical activity are an important aspect of social support; having conversations about when and how to be active can contribute to better health outcomes and self-efficacy $[8,13]$. In rounds 2 and 3 , over three-quarters of students discussed exercise with their families, and $40 \%$ reported having conversations specifically about the AHPC at least every other day.

At school, $50 \%$ of the respondents discussed exercise with their facilitating teachers at least once; this is notable given that in many cases, the teachers were not physical education or health educators, but rather teachers of subjects such as mathematics, history, or social studies. With respect to Challenge-specific discussions, $77 \%$ of respondents talked about aspects of the Challenge with their teachers at least once. Although this number is high, we find it curious that $23 \%$ of the respondents said that they never discussed the AHPC with their teacher; involvement of teachers was found in our prior work to be a key aspect of Challenge success in schools $[14,15]$.

In addition to having conversations with adults, students also discussed the Challenge with their peers. Of the survey respondents, $59.6 \%$ discussed the Challenge with other participants at least weekly, and to a lesser extent with students not participating (47\%).

Conversations mediated within the game, however, were not as successful. In the changes to the game that were introduced during the second round of competition, the interface allowed students to set a "status message" for their 


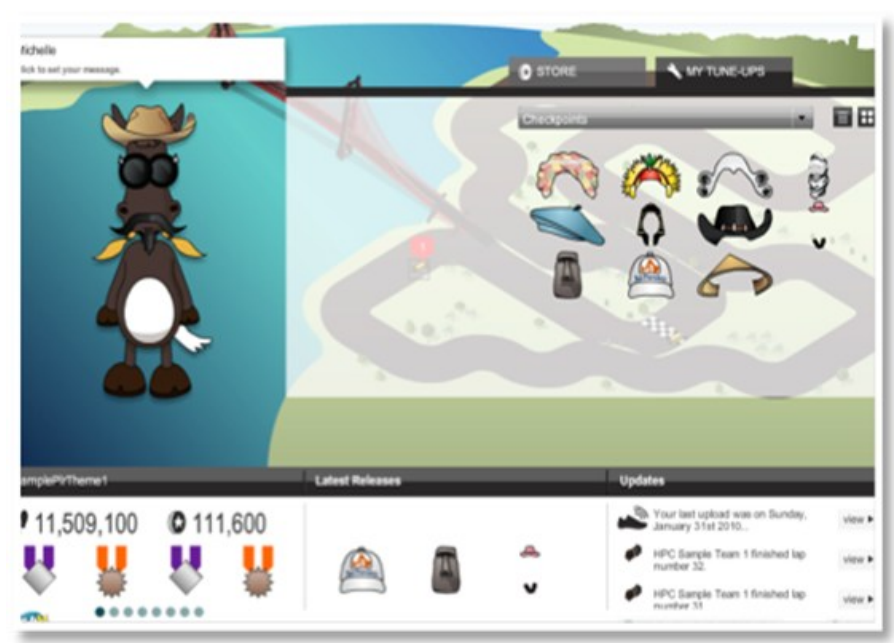

Figure 2. Game interface screenshot showing customizable horse avatar with status message (top left), items to purchase with virtual currency (top right), award ribbons (bottom left), and various game-related updates (bottom right)

horse avatars (see Fig. 2). Survey respondents reported never $(48 \%)$ or rarely $(24 \%)$ updating these messages; these survey results matched what we observed and discussed with students during the site visits. The students had trouble in understanding who could see the messages, and what to write. As a result, the most common status we observed was a simple "Hello."

We see three potential ways to improve mediated conversations within the games. First, for short social-media style status messages, aggregating them in a stream may increase their impact; in the game interface, the messages were tucked in the bottom-right corner, and were easy to ignore. Second, for messages intended for peers, providing scaffolding on how to write engaging messages may be helpful. This recommendation is in line with prior research on health-related messaging for adolescents [16]. A study by Toscos et al found that adolescents playing a text messaging physical activity intervention also struggled in creating "motivating" messages for their peers. Finally, designing ingame activities that foster friendships with other players has been shown within the field of video game design as an effective way of increasing the probability of longer-term engagement with a given game [17].

\section{B. Encouragement and Praise}

In addition to general conversations about activity, we also inquired specifically about encouragement and praise given to students. The majority of parents $(84 \%)$ said they had encouraged their child to be physically active or play sports at least a few times in the past week. The students, however, did not perceive their parents as being so "encouraging," with $40 \%$ of respondents reporting their parents as providing encouragement often or very often during round 2 and $39.1 \%$ doing so in round 3. Similarly, student perceived teacher and friend encouragement was lower than one might expect. A mere $30.2 \%$ of respondents reported frequent teacher encouragement in round 2; this number did, however, jump to $48.2 \%$ during round 3 . A likely explanation for this change is that by round 3 , less enthusiastic teachers may have dropped out of the challenge, or teachers emphasized the competition more in the final stages. Friend encouragement was the lowest of all, at $23.8 \%$ in round 2 and $36.3 \%$ in round 3 .

Having the game interface provide praise did not prove effective; during rounds 2-3, the game included virtual "ribbon" awards for individual and team improvements over the course of the competition (see Fig. 2). During our site visits to competing schools, the students did not show any interest in the ribbons; when prompted to discuss them, the students recognized what the ribbons were for, but we did not meet a single student who was actively proud of his or her ribbon. Increasing the social visibility of ribbons would also increase their perceived worth; this is similar to other findings in the literature about providing virtual badges in pervasive health interventions [18]. We suggest that if including virtual rewards, they should either be personally relevant to the students (e.g. achievement of a goal that he/she has personally chosen), or be recognized in-person by teachers and students (for instance, by having the teacher announce awards during class, or personally congratulate the student for his or her achievement).

\section{Reminders}

Reminders about being physically active (e.g. "Remember to wear your pedometer") from family stayed consistent between rounds 2 and 3 (38.7\% for round 2 and $38.3 \%$ for round 3 ). As with encouragement, reminders from teachers and friends increased as the Challenge neared to a close. Teacher reminders increased from $28.1 \%$ to $45.6 \%$. Friend reminders increased from $21.2 \%$ to $32.7 \%$. Again it is unclear whether this is due to selective participation in round 3 , a sense of urgency as the competition drew to a close, or both.

\section{Co-participating in Physical Activity}

Getting physical activity with another person can increase and sustain activity-related habits [19-22]. Across rounds 2 and 3, students reported that friends always or frequently joined them when physically active (47.6\% and $50.9 \%$ respectively). Adults were far less likely to co-participate in activities, however. While a small number of teachers (15\%) participated in physical activity with students during round 2 , the majority $(72 \%)$ rarely or never co-participated in physical activity with their students. In round 3, participation by teachers increased to $37 \%$; again, it is unclear whether this increase was due to selective dropout of less motivated teachers. Although teachers may not have joined students in being active, this does not mean that the teachers were uninterested in student physical activity; in fact, teachers reported making a number of behind-the-scenes accommodations for their students such as creating lessons involving physical activity, negotiating access to gyms and playground equipment, and organizing recreational sport opportunities for students during lunch, 


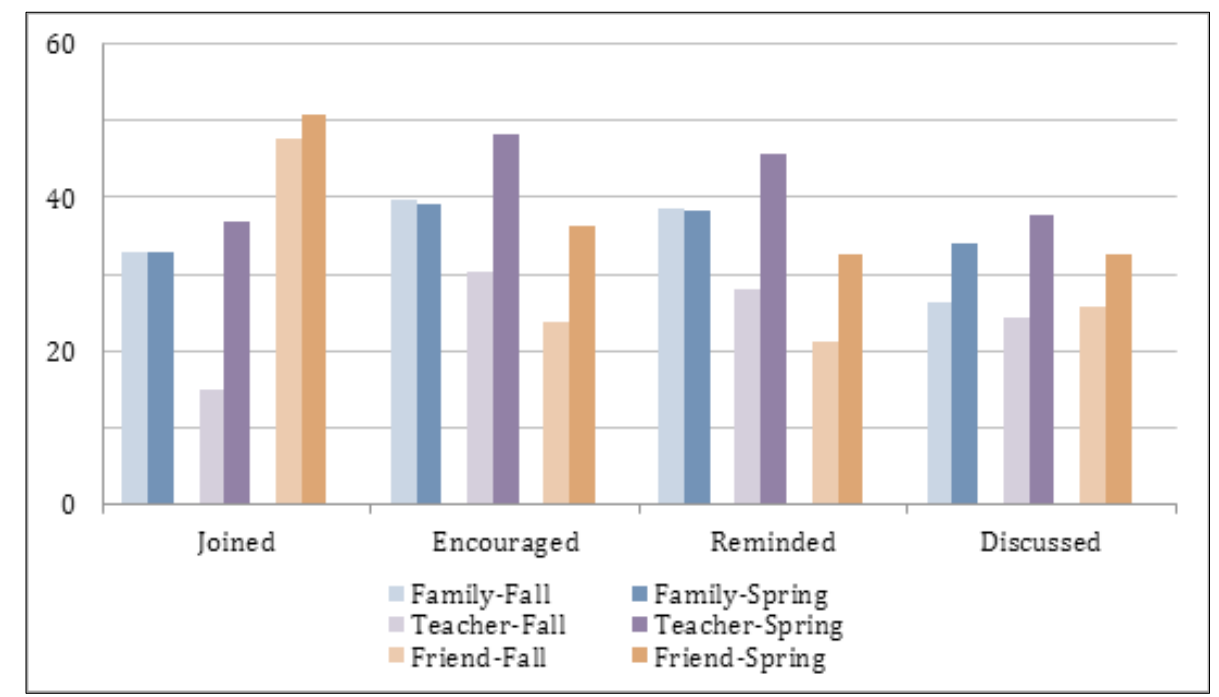

Figure 3. Percentage of respondents reporting social support from others in round 2 (fall) and round 3 (spring)

recess, and after school. Likely this work was invisible to the students in the competition.

Similarly, parents provided access for students to get physical activity, but were less likely to co-participate in physical activities with their children. Sixty-two percent of parents had transported their child to a place where he or she could do physical activity or play sports in the past week, and $49 \%$ paid fees for participation in lessons or a sports team. Overall, $33 \%$ of responding students reported that their parents joined them in physical activity often or very often. Why was this number not higher? There are a few possible reasons for lack of intergenerational physical activity. Parents might be used to playing the role of spectators at organized sporting events for children, where they cheer the children rather than actually participating. Similarly, many fitness facilities offering structured exercise for adults may not allow participation of children under a certain age. Unstructured physical activity (e.g. "free play") might be different for children and adults, in terms of what appeals to and is considered normal for that group. We believe that intergenerational physical activity is an area that may be fruitful to target in pervasive health interventions for youth physical activity; we return to this point later in the paper.

\section{E. Social Comparison}

Social comparison theory [23] suggests that people are motivated to compare themselves to others; these comparisons can have positive results (e.g. seeing that you are doing quite well in comparison to your peers) or negative results (e.g. doing poorly compared to peers).

With respect to school versus school comparison, students were interested in seeing how their "team" compared to others. Checking team status compared to other schools ranked as a popular activity: $46 \%$ did so at least every other day, and $69 \%$ of the respondents did so at least weekly. In fact, the interface appeared to succeed at its core goals of showing students their personal steps and their school's position in the race, letting them interact with their avatars, and serving as a desired online activity.

We found little evidence, however, that students were engaging in individual social comparison using the game interface. While individual student step counts were not publicly available to other players, the game featured a virtual currency earned through physical activity participation. As such, the currency had the potential to act as a proxy for one's personal standing in the game; the more currency the students had, the more customizations they could make to their horse avatars. The interest in other people's horses, however, was split: $56.1 \%$ looked at the other horses less than once a week (31.6\% never looking at all). Roughly a quarter of the students looked at the horses several times a week, with $9.2 \%$ reporting daily views of classmates' horses.

In face to face settings, as opposed to via the game interface, we did observe instances of social comparison during the focus groups, although rarely based on actual stepcount data. At one school, for example, several of the boys reported feeling that they were responsible for a large number of the school's steps. Several girls responded that it was not true, and noted the unfairness of the comparison, since most girls' sports were out of season at the time. In this case, peers had been comparing themselves to each other, but as we found repeatedly, the focus was on relative ability to contribute to the interschool competition, rather than strict local social comparison. This conclusion was supported by statements from teachers saying that the sense of being a part of a team was important motivator for the students, especially ones not otherwise involved in team sports. In addition, our findings indicated the students enjoyed the school competition aspect 


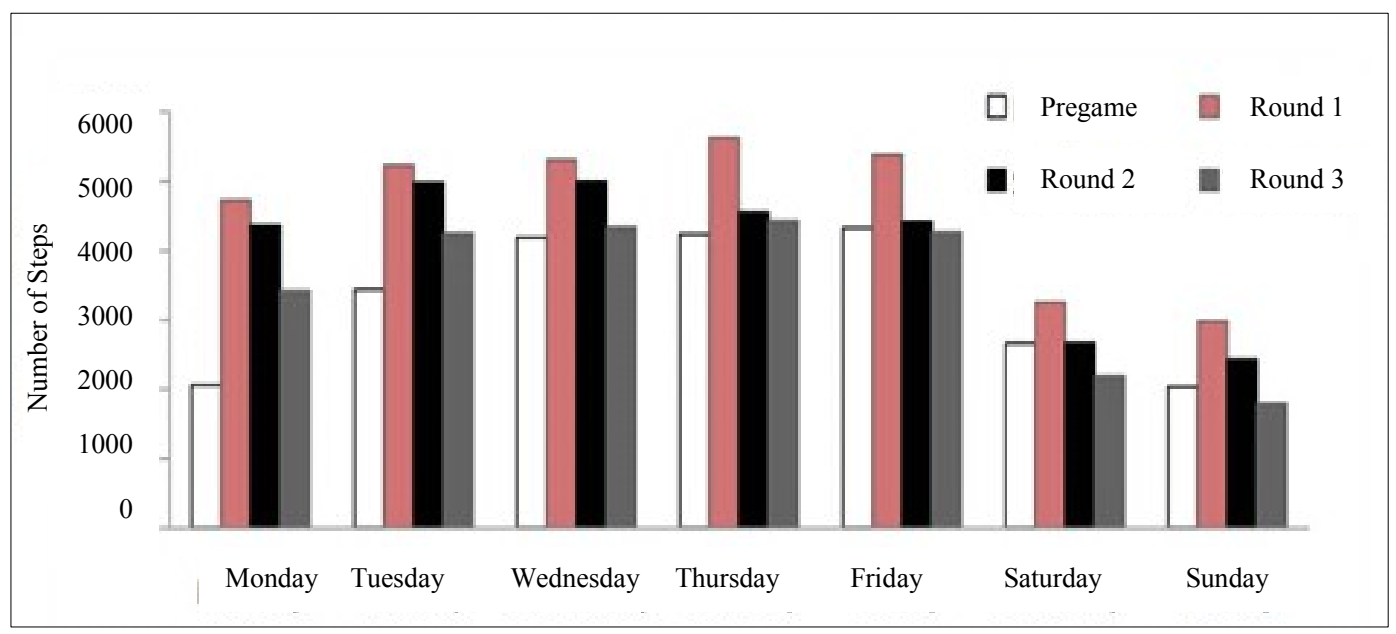

Figure 4. Average weekly distribution of steps

and took their responsibility of competing for the school seriously (at least initially). Given these findings, we suggest that there may be benefits to supporting team-based competition and comparisons.

\section{DISCUSSION: DRAWING IN SPECTATORS}

Although students did not always recognize when they were receiving social support, the actions of adults that remained largely "invisible" to the students contributed to accrual of physical activity. Throughout the competition, students reported participation in a variety of active pursuits; the majority walked, ran, practiced on a sports team, played outside, played active video games, or did physically demanding chores one or more times a week. Given these findings, we observed a trend that participant step counts decreased during the weekends. The average number of steps logged on weekends was significantly smaller than the number logged on weekdays for the pre-game period and all three rounds (Pre-game: $t(1857)=12.63, p<.001$ ); Round1: $t(9213)=39.36, p<.001)$; Round2: $t(4252)=29.89, p<$ $.001)$; Round3: $t(3729)=28.90, p<.001)$. On average, participants logged 4686.70 steps on weekdays $(\mathrm{SD}=348.56)$ and 2554.92 on weekends ( $\mathrm{SD}=213.28)$. This difference was found even when excluding cases in which students did not wear their pedometers.

Why did this drop occur? Some students might have viewed the AHPC as a school project and tended not to change their home behaviors during the weekends, but a more likely explanation for these results could be that the home environment of the students provided fewer "obvious" opportunities for physical activities in general compared to the school environment (e.g., in terms of participating in selfinitiated activities by friends and peers or extracurricular AHPC activities). At school, the students were required to participate in curricular physical activities, and were provided opportunities for unstructured free play. These opportunities for being physically active are less likely to be present during the weekends and students have to be either internally motivated to be active or have parents that get them to be active (e.g. by funding or providing transport to organized sports, encouraging active play, or participating in physical activity with the child). The survey results reported that parents tended to verbally encourage their kids to be physically active (or support them by transporting them), but were less likely to join the kids for physical activities. The parents largely were spectators in their child's pursuit of physical activity.

Thus, we ask the following: what if spectators could be temporarily brought into pervasive health games as players? A common mechanic of video game design is to introduce small "bonus" challenges, or puzzles that require the cooperation of multiple players in order to be successful [17]. We envision that spectators could be drawn in simply by providing additional pedometers that could be used by family members as part of smaller challenges to be completed over the weekend. Students could then return the pedometers to school, allowing them to be synched to the larger competition. This sort of spectator involvement may achieve two goals: it may encourage intergenerational physical activity while also increasing weekend activity levels. Similarly, to increase a sense of team spirit and solidarity, additional pedometers could be given to other students or staff in a given school in order to provide an extra "boost" to the team.

In school settings, however, we stress that the timing of these additional challenges should be left at the discretion of individual teachers. The reasoning behind this suggestion is twofold. First, having the support and buy in of a teacher increases the likelihood that the challenges will be accepted rather than ignored. Second, allowing the teacher opportunity to choose the timing of the bonus challenges gives flexibility in providing a boost at times when individual or group motivation is waning; this recommendation may also hold for other types of small-group competition moderated by a facilitator (e.g. a physical activity challenge for adult office workers).

\section{CONCLUSIONS}

In this paper, we provided information on how social support was enacted within the context of a pervasive health game played by American children. Children are unique 
consumers of health interventions in that they do not have as much agency over their daily lives. Parents, teachers, and other adults have quite a bit of control over a child's activities and decision-making. Thus there is a role for not only considering how individuals interact with pervasive health interventions, but also considering ecosystem of social support received by intervention users, whether from other people or from the intervention itself.

We found that peers were the most likely to join students in the program for physical activity. Teachers and parents played important support roles that often went unacknowledged by the students. Attempts to facilitate social support within the game interface were underutilized and underappreciated by students; even so, we believe that providing support mediated through game interfaces shows promise, but requires attention to user interface design and what motivates players.

Adults infrequently joined children for physical activity; we believe this represents a gap in pervasive health games for children. Intergenerational physical activity framed as short-term "bonus" challenges may be appealing and increase child and adult physical activity alike.

\section{ACKNOWLEDGMENTS}

Support for this work was provided by Humana. The first author also received support for this work from the Tronzo Endowment at time of writing.

\section{REFERENCES}

[1] M. J. M. C. A. Paw, W. M. Jacobs, E. P. G. Vaessen, S. Titze, and W. v. Mechelen, "The motivation of children to play an active video game," Journal of Science and Medicine in Sport, vol. 11, p. 163, 2008.

[2] T. Baranowski, D. Abdelsamad, J. Baranowski, T. M. O'Connor, D. Thompson, A. Barnett, E. Cerin, and T.-A. Chen, "Impact of an active video game on healthy children's physical activity," Pediatrics, vol. 129, pp. e636-e642, 2012.

[3] J. Sallis, J. Prochaska, and W. Taylor, "A review of correlates of physical activity of children and adolescents," Medicine \& Science in Sports \& Exercise, vol. 32, p. 963, 2000.

[4] G. J. Norman, B. A. Schmid, J. F. Sallis, K. J. Calfas, and K. Patrick, "Psychosocial and Environmental Correlates of Adolescent Sedentary Behaviors," Pediatrics, vol. 116, pp. 908-916, October 1, 2005 2005.

[5] J. F. Sallis and K. Glanz, "The Role of Built Environments in Physical Activity, Eating, and Obesity in Childhood," The Future of Children, vol. 16, pp. 89-108, 2006.

[6] S. Cohen and T. A. Wills, "Stress, social support, and the buffering hypothesis," Psychological bulletin, vol. 98, pp. 310-357, 1985.

[7] B. H. Gottlieb and A. E. Bergen, "Social support concepts and measures," Journal of psychosomatic research, vol. 69, pp. 511-520, 2010.
[8] B. Lakey and S. Cohen, "Social support theory and measurement," Social support measurement and intervention: A guide for health and social scientists, pp. 29-52, 2000.

[9] M. W. Beets, B. J. Cardinal, and B. L. Alderman, "Parental social support and the physical activityrelated behaviors of youth: a review," Health Education \& Behavior, vol. 37, pp. 621-644, 2010.

[10] D. A. Lown and C. L. Braunschweig, "Determinants of physical activity in low-income, overweight African American girls," American Journal of Health Behavior, vol. 32, pp. 253-259, 2008.

[11] E. Eiriksdottir, D. Kestranek, A. Miller, E. S. Poole, Y. Xu, R. Catrambone, and E. Mynatt, "Assessment of Health Games in Secondary Schools: An Investigation of the American Horsepower Challenge 2009-2010. Georgia Institute of Technology," Georgia Institute of Technology, Atlanta, GA, USA2010.

[12] J. F. Sallis, R. M. Grossman, R. B. Pinski, T. L. Patterson, and P. R. Nader, "The development of scales to measure social support for diet and exercise behaviors," Preventive medicine, vol. 16, pp. 825836, 1987.

[13] N. E. Sherwood and R. W. Jeffery, "The behavioral determinants of exercise: implications for physical activity interventions," Annual review of nutrition, vol. 20, pp. 21-44, 2000.

[14] A. Miller, E. Poole, Y. Xu, E. Eiriksdottir, D. Kestranek, R. Catrambone, and E. Mynatt, "The work of play: supporting a pervasive health behavior change intervention for us middle school students," presented at the Proceedings of the ACM 2012 conference on Computer Supported Cooperative Work, Seattle, Washington, USA, 2012.

[15] E. S. Poole, A. D. Miller, Y. Xu, E. Eiriksdottir, R. Catrambone, and E. D. Mynatt, "The place for ubiquitous computing in schools: lessons learned from a school-based intervention for youth physical activity," presented at the Proceedings of the 13th international conference on Ubiquitous computing, Beijing, China, 2011.

[16] T. Toscos, A. Faber, K. Connelly, and A. M. Upoma, "Encouraging physical activity in teens Can technology help reduce barriers to physical activity in adolescent girls?," in Pervasive Computing Technologies for Healthcare, 2008. PervasiveHealth 2008. Second International Conference on, 2008, pp. 218-221.

[17] J. Schell, The Art of Game Design: A book of lenses: Morgan Kaufmann, 2008.

[18] S. A. Munson and S. Consolvo, "Exploring goalsetting, rewards, self-monitoring, and sharing to motivate physical activity," presented at the PervasiveHealth 2012, San Diego, CA, 2012.

[19] S. J. H. Biddle and C. Bailey, "Motives for participation and attitudes toward physical activity of 
adult participants in fitness programs," Perceptual and Motor Skills, vol. 61, pp. 831-834, 1985.

[20] A. V. Carron, W. N. Widmeyer, and L. R. Brawley, "Group cohesion and individual adherence to physical activity," Journal of Sport \& Exercise Psychology, 1988.

[21] K. S. Spink and A. V. Carron, "The effects of team building on the adherence patterns of female exercise participants," Journal of Sport \& Exercise Psychology, 1993.
[22] S. N. Fraser and K. S. Spink, "Examining the role of social support and group cohesion in exercise compliance," Journal of behavioral medicine, vol. 25, pp. 233-249, 2002.

[23] L. Festinger, "A theory of social comparison processes," Human relations, vol. 7, pp. 117-140, 1954. 